\title{
Rhizosphere bacteriome of the medicinal plant Sapindus saponaria L. revealed by pyrosequencing
}

\author{
A. Garcia ${ }^{1}$, J.C. Polonio ${ }^{1}$, A.D. Polli ${ }^{1}$, C.M. Santos ${ }^{1}$, S.A. Rhoden ${ }^{2}$, \\ M.C. Quecine ${ }^{3}$, J.L. Azevedo ${ }^{3}$ and J.A. Pamphile ${ }^{1}$ \\ ${ }^{1}$ Laboratório de Biotecnologia Microbiana, Departamento de Biotecnologia, \\ Genética e Biologia Celular, Universidade Estadual de Maringá, \\ Maringá, PR, Brasil \\ ${ }^{2}$ Instituto Federal Catarinense, Campus São Francisco do Sul, \\ São Francisco do Sul, SC, Brasil \\ ${ }^{3}$ Departamento de Genética, Escola Superior de Agricultura Luiz de Queiroz, \\ Universidade de São Paulo, Piracicaba, SP, Brasil \\ Corresponding author: J.A. Pamphile \\ E-mail: japamphile@uem.br / prof.pamphile@gmail.com
}

Genet. Mol. Res. 15 (4): gmr15049020

Received July 21, 2016

Accepted September 9, 2016

Published November 3, 2016

DOI http://dx.doi.org/10.4238/gmr15049020

Copyright (C) 2016 The Authors. This is an open-access article distributed under the terms of the Creative Commons Attribution ShareAlike (CC BY-SA) 4.0 License.

\begin{abstract}
Sapindus saponaria L. of Sapindaceae family is popularly known as soldier soap and is found in Central and South America. A study of such medicinal plants might reveal a more complex diversity of microorganisms as compared to non-medicinal plants, considering their metabolic potential and the chemical communication between their natural microbiota. Rhizosphere is a highly diverse microbial habitat with respect to both the diversity of species and the size of the community. Rhizosphere bacteriome associated with medicinal plant $S$. saponaria is still poorly known.
\end{abstract}


The objective of this study was to assess the rhizosphere microbiome of the medicinal plant $S$. saponaria using pyrosequencing, a cultureindependent approach that is increasingly being used to estimate the number of bacterial species present in different environments. In their rhizosphere microbiome, 26 phyla were identified from 5089 sequences of $16 \mathrm{~S}$ rRNA gene, with a predominance of Actinobacteria (33.54\%), Acidobacteria (22.62\%), and Proteobacteria (24.72\%). The rarefaction curve showed a linear increase, with 2660 operational taxonomic units at 3\% distance sequence dissimilarity, indicating that the rhizosphere microbiome associated with $S$. saponaria was highly diverse with groups of bacteria important for soil management, which could be further exploited for agricultural and biotechnological purposes.

Key words: Pyrosequencing; Rhizosphere; Diversity; Culture-independent approach; Sapindus saponaria L.

\section{INTRODUCTION}

In Brazil, biotechnological research has targeted the diversity of microorganisms because of the potential for discovery of new bioactive compounds or bioprocesses (Schulz and Boyle, 2005; de Oliveira Costa et al., 2012; García et al., 2012b; Rhoden et al., 2012; Miguel et al., 2013; Polonio et al., 2015). Studies on microbiota associated with plants are important to understand and predict the spatial distribution of microbial communities and the ecosystem responses to global climate change (Singh et al., 2010). Most plant-microbe community relationships studied deal with plants that are economically important or have medicinal properties.

Sapindus saponaria L., belonging to the Sapindaceae family, is popularly known as soldier soap. The Sapindus species extracts have antimicrobial, spermicidal, antiulcer, antifungal, and anti-inflammatory properties (Pelegrini et al., 2008). Studies by Garcia et al. (2012a) demonstrated the antimicrobial activity of secondary metabolites from endophytic fungi isolated from $S$. saponaria.

Rhizosphere is a highly diverse microbial habitat in terms of both the diversity of species and the size of the community. Even though bacteria are the most abundant soil microorganisms (Gans et al., 2005; Pelczar et al., 2011), only a fraction of them can be cultivated in the laboratory, and there are many unidentified bacterial species in the soil (Gans et al., 2005; Schloss and Handelsman, 2006).

Cultivation-independent methods, such as pyrosequencing, for the study of microbial diversity are becoming increasingly popular for the estimation of the number of bacterial species present in different environments. The high performance and low cost of pyrosequencing allow a comprehensive assessment of the diversity of bacteria in the soil (Roesch et al., 2007). In addition, the 16S rRNA gene is an important molecular tool in this process, assisting in the identification and study of bacterial communities.

The complexity and specificity of rhizosphere habitat is still poorly known. Therefore, the objective of this study was to analyze the microbiome of $S$. saponaria rhizosphere.

Genetics and Molecular Research 15 (4): gmr15049020 


\section{MATERIAL AND METHODS}

\section{S. saponaria}

The $S$. saponaria tree studied in this study was located in the campus of Universitdade

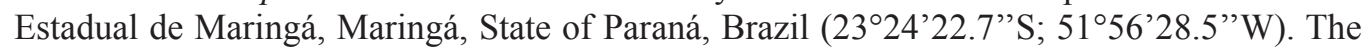
samples used for analyses were collected in December 2013.

\section{Physicochemical composition of $S$. saponaria rhizosphere}

The physicochemical analysis of $S$. saponaria rhizosphere samples was conducted by Laboratório Rural de Maringá, Maringá, Brazil.

\section{Total DNA extraction from $S$. saponaria rhizospheric soil}

Considering the definition of rhizosphere (Morgan and Whipps, 2001) and the size of adult trees and their roots, the samples of $S$. saponaria rhizospheric soil were collected from four points at a distance of $50 \mathrm{~cm}$ from the tree trunk, near the roots. Soil samples were collected from an average depth of $10 \mathrm{~cm}$ with a Dutch auger and were sieved to remove lumps, roots, and leaves. The samples were then mixed and total DNA was extracted using the PowerSoil DNA Isolation Kit (MO BIO Laboratories, Carlsbad, CA, USA), following the manufacturer protocol.

\section{Analysis of rhizosphere microbiome via pyrosequencing}

The quantity and quality of the pooled DNA extracted from the soil was assessed on $1 \%$ agarose gel. Bacterial diversity was assessed using the $16 \mathrm{~S}$ rRNA gene, which was amplified using primers $968 \mathrm{~F}$ (Nielsen et al., 1999) and 1378R. PCR was performed on a final volume of $50 \mu \mathrm{L}$, containing $1 \mathrm{X}$ enzyme buffer, $5 \mathrm{mM} \mathrm{MgCl}, 10 \mathrm{mM}$ dNTPs, $0.1 \mathrm{M}$ each primer, and $2 \mathrm{U}$ Taq DNA polymerase. The amplification was performed in a thermal cycler, with an initial denaturation at $95^{\circ} \mathrm{C}$ for $5 \mathrm{~min}$, followed by 35 cycles of denaturation at $94^{\circ} \mathrm{C}$ for $30 \mathrm{~s}$, annealing at $62^{\circ} \mathrm{C}$ for $30 \mathrm{~s}$, and extension at $72^{\circ} \mathrm{C}$ for $40 \mathrm{~s}$, and a final extension at $72^{\circ} \mathrm{C}$ for $10 \mathrm{~min}$. The PCR products were assessed using $1 \%$ agarose gel electrophoresis.

The PCR products were purified using Illustra GFX PCR DNA and Gel Band Purification Kit (GE Healthcare, Buckinghamshire, UK), following the manufacturer protocol. The purity and quantity of the amplicons were checked on 1\% agarose gel. The PCR products of each treatment were mixed proportionally and were sequenced by a 454 Sequencing System (Roche Applied Science, Branford, CT, USA), using the pyrosequencing method.

\section{Analysis of pyrosequencing data}

DNA sequences were selected based on their quality and size using the Pipeline Initial Processing tool available in the Ribosomal Database Project (RDP) Pipeline. Selection was based on the quality of bases, size of the fragments, identified sequences of the primers, and presence of unidentified bases. In order to obtain a set of sequences with satisfactory quality for analysis, only the sequences with scores greater than 20 and with bases having maximum probability of $1 \%$ error were used. Sequences with unidentified bases and sequences smaller

Genetics and Molecular Research 15 (4): gmr15049020 
than $380 \mathrm{bp}$ were excluded. There was a $20 \%$ tolerance range for similarity with primers (without the adapter sequences). Thus, the adapter sequences were removed from the primerflanking region, eliminating the risk of truncated sequences reducing the quality and interfering with the classification of the sequences.

Sequences were classified and species accumulation (thinning) was analyzed using the software Mothur v.1.34.4, which performs a similarity analysis against the RDP database containing tested gene sequences of $16 \mathrm{~S}$ rRNA that have been previously evaluated for quality. The search parameters were based on similarity, with higher similarity resulting in the identification of the lower taxonomic levels. Analysis of sequence similarity was performed according to the recommended system: domain, $>0 \%$; phylum, $>75 \%$; class, $>85 \%$; order, $>91 \%$; family, $>92 \%$; genus, $>95 \%$; and species, $>97 \%$.

\section{RESULTS}

\section{Rhizosphere bacteriome}

Totally, 5367 bacterial 16S rRNA gene sequences were identified in the rhizosphere of $S$. saponaria, through pyrosequencing. After screening via RDP Pipeline, we obtained 5089 sequences.

On comparison of these sequences against RDP database, 26 phyla were identified (Figure 1), with a predominance of Actinobacteria (33.54\%), Acidobacteria (22.62\%), and Proteobacteria $(24.72 \%)$. Other phyla were identified at rates below $6 \%$ of the total number of sequences. Within the phylum Actinobacteria, the orders Actinomycetales (18.04\%), Solirubrobacterales (12.1\%), Acidimicrobiales (2.77\%), and five other orders at rates less than $1 \%$ of the total number of sequences were observed. Among the Acidobacteria, $19.69 \%$ of the sequences were divided into 12 taxonomic groups classified only at the phylum level, whereas $2.93 \%$ were classified at the order level. Proteobacteria were distributed into 33 orders, of which Rhizobiales (6.07\%), Myxococcales (4.68\%), Syntrophobacterales (3.42\%), Rhodospirillales (1.59\%), Desulfuromonadales (1.40\%), and Xanthomonadales (1.20\%) were most prominent.
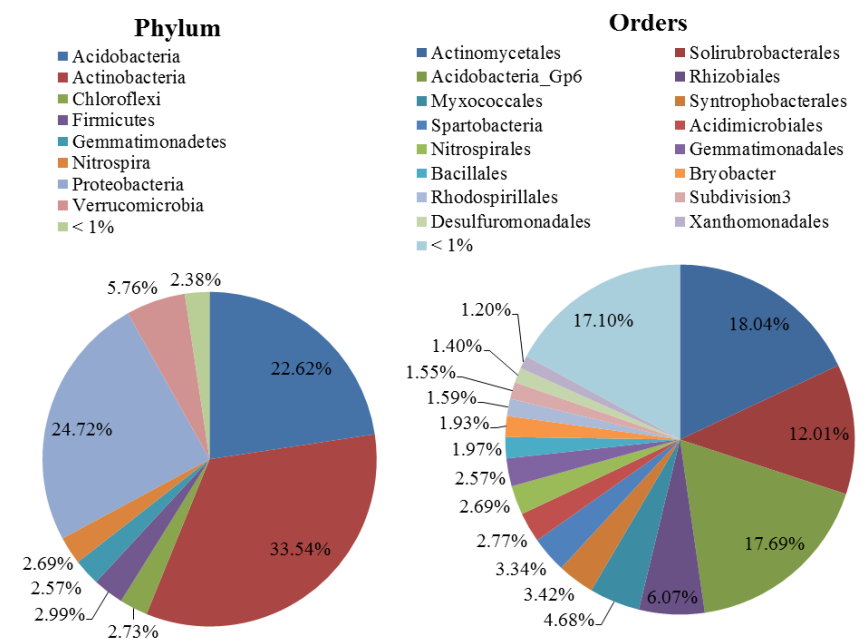

Figure 1. Taxonomic distribution of soil bacterial communities associated with the plant Sapindus saponaria L., at the phylum and order levels.

Genetics and Molecular Research 15 (4): gmr15049020 
In the soil microbiome, we found nine sequences belonging to the class Gammaproteobacteria. Other phyllum, besides Proteobacteria, were present at a rate less than $1 \%$ in the soil microbiome.

Among the Firmicutes, we obtained 100 sequences (1.97\%) belonging to the order Bacillales, whereas $0.22 \%$ Lactobacillales were present. Among Bacteroidetes, the order Flavobacteriales presented only four sequences.

Figure 2 shows a rarefaction curve depicting linear increase in bacterial diversity, measured by the richness of operational taxonomic units (OTUs) at a taxonomic level of $97 \%$ identity, based on the number of sequences obtained via pyrosequencing (Table 1). At this level of identity, OTUs would be formed by closely related species with similar phenotypic properties (Keswani and Whitman, 2001; Qi et al., 2012). Statistical analyses were performed and Shannon index, Simpson index, and Chaol estimator were calculated to estimate the biodiversity of microbes in the sample (Table 1).

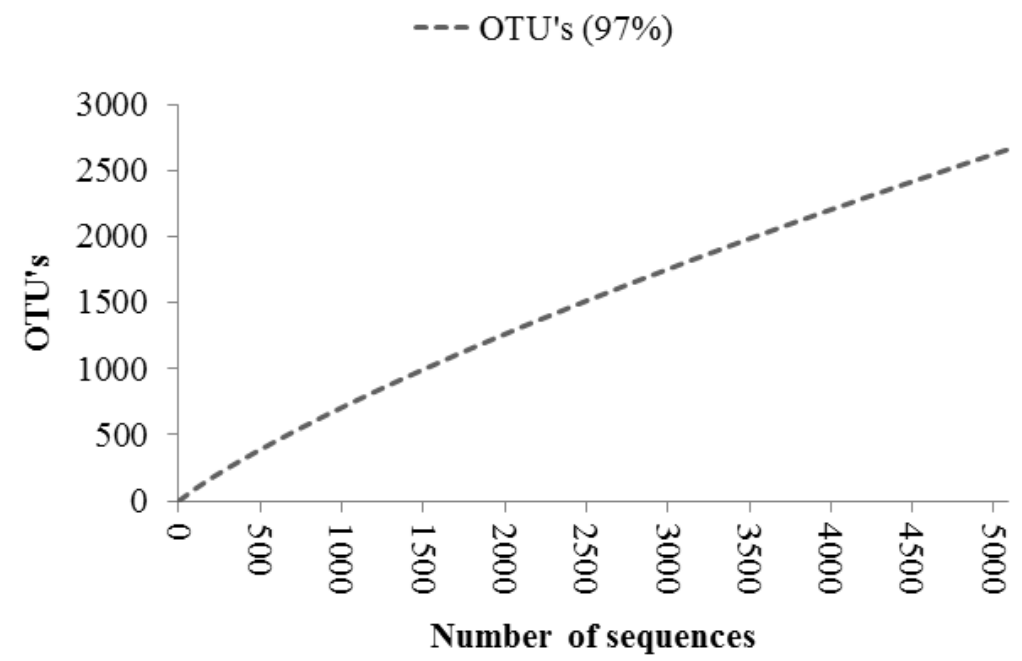

Figure 2. Rarefaction analysis of Sapindus saponaria rhizosphere. Rarefaction curve was constructed using the Mothur software and shows OTUs with differences not exceeding $3 \%$.

Table 1. Biodiversity indexes for Sapindus saponaria L. rhizosphere microbiome.

\begin{tabular}{l|c|c|c}
\hline Index & Order (91\%) & Genus (95\%) & Species (97\%) \\
\hline Simpson & 0.0098 & 0.0049 & 0.0027 \\
\hline Shannon & 6.013 & 6.8126 & 7.237 \\
\hline Chao1 & 4999.887 & 8587.804 & $10,790.46$ \\
\hline OTUs & 1563 & 2209 & 2660 \\
\hline
\end{tabular}

\section{Chemical composition of the $S$. saponaria rhizosphere}

The analyses of macro- and micro-nutrient contents of the S. saponaria rhizosphere are demonstrated in Table 2.

Genetics and Molecular Research 15 (4): gmr15049020 
Table 2. Physicochemical properties of rhizospheric soil associated with Sapindus saponaria L.

\begin{tabular}{|c|c|}
\hline Parameter & Result \\
\hline \multicolumn{2}{|l|}{ Soil acidity } \\
\hline $\mathrm{pH}$ in calcium chloride & 5.70 \\
\hline $\mathrm{pH}$ in water & 6.45 \\
\hline pH in SMP buffer & 6.73 \\
\hline Total acidity $\left[\mathrm{H}^{+}\right]\left(\mathrm{cmol}_{\mathcal{C}} / \mathrm{dm}^{3}\right)$ & 2.90 \\
\hline \multicolumn{2}{|l|}{ Physical composition of the soil } \\
\hline Sand $(\%)$ & 37.00 \\
\hline Clay $(\%)$ & 56.00 \\
\hline Silt (\%) & 7.00 \\
\hline \multicolumn{2}{|l|}{ Macronutrients and micronutrients } \\
\hline Organic matter $\left(\mathrm{g} / \mathrm{dm}^{3}\right)$ & 29.11 \\
\hline Carbon $\left(\mathrm{g} / \mathrm{dm}^{3}\right)$ & 16.89 \\
\hline Phosphorus $\left(\mathrm{mgP} / \mathrm{dm}^{3}\right)$ & 9.87 \\
\hline Potassium $\left(\mathrm{cmol}_{\mathrm{c}} / \mathrm{dm}^{3}\right)$ & 0.47 \\
\hline Calcium + magnesium $\left(\mathrm{cmol}_{\mathrm{c}} / \mathrm{dm}^{3}\right)$ & 5.67 \\
\hline Calcium $\left(\mathrm{cmol}_{\mathrm{c}} / \mathrm{dm}^{3}\right)$ & 4.38 \\
\hline Magnesium $\left(\mathrm{cmol}_{\mathcal{c}} / \mathrm{dm}^{3}\right)$ & 1.30 \\
\hline Hydrogen + aluminum $\left(\mathrm{cmol}_{\mathrm{c}} / \mathrm{dm}^{3}\right)$ & 2.90 \\
\hline Aluminum & - \\
\hline Sulfur $\left(\mathrm{mg} / \mathrm{dm}^{3}\right)$ & 3.58 \\
\hline Copper $\left(\mathrm{mg} / \mathrm{dm}^{3}\right)$ & 9.05 \\
\hline Zinc $\left(\mathrm{mg} / \mathrm{dm}^{3}\right)$ & 5.40 \\
\hline Iron $\left(\mathrm{mg} / \mathrm{dm}^{3}\right)$ & 30.50 \\
\hline Manganese $\left(\mathrm{mg} / \mathrm{dm}^{3}\right)$ & 78.50 \\
\hline Sodium $\left(\mathrm{mg} / \mathrm{dm}^{3}\right)$ & 2.15 \\
\hline Boron $\left(\mathrm{mg} / \mathrm{dm}^{3}\right)$ & 0.11 \\
\hline Nitrogen & - \\
\hline Chlorine & - \\
\hline \multicolumn{2}{|l|}{ Other components } \\
\hline Crude protein & - \\
\hline
\end{tabular}

\section{DISCUSSION}

Rhizosphere is a microbial ecosystem occupied by specific microorganisms. Thus, the study of its microbial diversity is of utmost importance to assess the predominant genera and to understand the possible ecological relationships between plant hosts, endophytes, and the soil microbiome.

The complex interaction between these environments and their microorganisms is still unknown. Mendes et al. (2011) showed that microbial communities in the soil could influence plant immunity against root pathogens. They demonstrated that members of Proteobacteria have the ability to suppress the activity of Rhizoctonia solani, an important pathogen of various crops, such as sugar beet, potatoes, and rice, and that plants could benefit directly or indirectly from the ability of these bacteria to control plant pathogens.

We investigated the rhizosphere bacterial community associated with the medicinal plant $S$. saponaria. The soil examined harbored a diverse community of bacteria. We also analyzed the chemical composition of the soil to investigate whether environmental factors, such as macro- and micro-nutrients or $\mathrm{pH}$, could explain bacterial richness in the rhizosphere. According to García-Salamanca et al. (2013), the taxonomical and functional structures of soil microbial communities are influenced by biotic and abiotic factors, including the physicochemical characteristics of the soil and presence of plants. The authors pointed out that plants exert selective pressure on the soil microbial population through modification

Genetics and Molecular Research 15 (4): gmr15049020 
of the physicochemical characteristics of the surrounding soil and by the excretion of exudates consisting of amino acids, organic acids, proteins, and other chemicals that act as chemoattractants or chemorepellents. The values obtained in our samples were consistent with those from normal agricultural soil. The soil microbial biomass carbon and nitrogen, and nitrification, are also significantly positively correlated to the soil pH (Kemmitt et al., 2006).

The index values for the 2660 OTUs of S. saponaria rhizosphere, at 3\% distance sequence dissimilarity, were much higher than the values obtained by García-Salamanca et al. (2013), who studied the bacterial diversity of maize rhizosphere. They obtained less than 60 OTUs from a relatively high $\mathrm{pH}$, carbonate-rich soil typical of Southern Spain. The $\mathrm{pH}$ of $S$. saponaria rhizosphere was 6.45 , which was less than that of maize rhizosphere from Spain ( $\mathrm{pH} 8.5)$. However, other S. saponaria and maize rhizosphere characteristics, such as sand (37.00 and $37.02 \%$, respectively) and clay texture (56.00 and $31.30 \%$, respectively), were similar. The number of microorganisms in the soil depends on environmental factors, such as the amount and type of nutrients, moisture content, degree of aeration, temperature, and $\mathrm{pH}$. Roesch et al. (2007) analyzed different types of soil from Brazil, USA, and Canada using pyrosequencing. They observed that the diversity of bacteria in the forest soil was higher than that in the agricultural soil. They highlighted $\mathrm{pH}$ as an important factor influencing this diversity. Similarly, Nacke et al. (2011) evaluated the bacterial community structure of different types of soil from forests and grasslands of Germany and concluded that the bacterial community composition and diversity, in the six types of soil environment, presented significant differences between the types of land use and forest. Furthermore, the structure of bacterial communities was largely dependent on the tree species and soil $\mathrm{pH}$.

Statistical diversity indexes, such as Shannon index, Simpson index, and Chao estimator, were calculated. Chaol estimator value for $S$. saponaria rhizosphere was 10,790.46. The Shannon and Simpson indexes were 7.237 and 0.0027 , respectively, for the Sapindus rhizosphere (present work) and 3.42 and 0.059, respectively, for maize rhizosphere (García-Salamanca et al., 2013), indicating that the bacterial community in the S. saponaria rhizosphere was more complex than the maize rhizosphere. Similar to the observations of García-Salamanca et al. (2013), the most predominant 16S rRNA gene sequences in the $S$. saponaria rhizosphere were those of Actinobacteria, Acidobacteria, and Proteobacteria.

The bacterial community within a plant is prone to the influences of host genotype and changes in the host physiology (Hallmann and Berg, 2006). In the soil environment, most bacterial species are heterotrophic and sporulated bacilli are common. Species of Bacillus, Clostridium, Arthrobacter, Pseudomonas, Rhizobium, Azotobacter, and Nitrobacter are usually present in the soil. Actinomycetes bacteria, including species of Nocardia, Streptomyces, and Micromonospora are present in hot, dry soil. These bacteria can degrade many complex substances and are important for improving the soil fertility (Pelczar et al., 2011). Furthermore, they are known for their ability to produce antibiotics. In this study, the actinomycetes were the most frequent group observed in the $S$. saponaria rhizosphere.

Johnston-Monje et al. (2016) studied the bacterial populations in juvenile maize rhizospheres, originating from both seed and soil, by $16 \mathrm{~S}$ rDNA fingerprinting and nextgeneration sequencing. They concluded that maize rhizospheres receive diverse bacteria from soil. Additionally, the rhizospheres are influenced by the genotype or treatment of the seed and are dominated by species of Proteobacteria, Actinobacteria, Bacteroidetes, and Firmicutes. As many dominant 16S rDNA sequences were observed in the rhizospheres grown in both sterile and non-sterile substrate, Johnston-Monje et al. (2016) also concluded that most common

Genetics and Molecular Research 15 (4): gmr15049020 
bacteria in juvenile maize rhizospheres are transmitted by the seeds.

According to Winston et al. (2014), understanding the relationship between microbes and Cannabis, a medicinally and economically important crop, can affect its agricultural practices, improving the ability of the plant to grow. They presented the first description of the endorhiza-, rhizosphere-, and bulk soil-associated microbiome of five distinct Cannabis cultivars using $16 \mathrm{~S}$ rRNA gene sequencing. The bacterial community of the endorhiza is significantly cultivarspecific. The control of cultivar and soil type showed that microbial community structure differs significantly between plant cultivars, soil types, and among the endorhiza, rhizosphere, and soil. Comparing the non-rhizospheric and rhizospheric soil, the authors showed that there is a preference for bacterial communities in the rhizosphere to reduce the abundance of Acidobacteria, associated with an increase in Proteobacteria and Actinobacteria numbers. The Actinobacteria can produce various secondary metabolites with antibiotic properties (Silva-Lacerda et al., 2016), which can be important to balance the microbiome.

The highly diverse microbiome of $S$. saponaria could be even more diverse, considering the fact that fungi were not evaluated. The high complexity network communication between bacteria, fungi, and plants may influence the composition of the microbiome. In addition, considering that the rarefaction analysis showed linear increase in the bacterial diversity, a higher number of reads from pyrosequencing analysis of the $S$. saponaria rhizosphere microbiome could provide more information about the rare or less prominent bacteria.

\section{CONCLUSION}

Thus, for the first time, bacterial taxonomic composition of the S. saponaria rhizosphere was described using pyrosequencing. The soil associated with the medicinal plant $S$ saponaria supported a high diversity of bacteria, considering the rarefaction analysis, which indicated that soil microbial diversity was even greater than measured.

\section{Conflicts of interest}

The authors declare no conflict of interest.

\section{ACKNOWLEDGMENTS}

Research supported by Conselho Nacional de Desenvolvimento Científico e Tecnológico (CNPq) (grant \#311534/2014-7 and \#447265/2014-8) and Fundação Araucária (grant FA-\#276/2014), and by Coordenação de Aperfeiçoamento de Pessoal de Nível Superior (CAPES) via scholarship to A. Garcia, J.C. Polonio, A.D. Polli, and C.M. Santos.

\section{REFERENCES}

de Oliveira Costa LE, de Queiroz MV, Borges AC, de Moraes CA, et al. (2012). Isolation and characterization of endophytic bacteria isolated from the leaves of the common bean (Phaseolus vulgaris). Braz. J. Microbiol. 43: 15621575. http://dx.doi.org/10.1590/S1517-83822012000400041

Gans J, Wolinsky M and Dunbar J (2005). Computational improvements reveal great bacterial diversity and high metal toxicity in soil. Science 309: 1387-1390. http://dx.doi.org/10.1126/science.1112665

Garcia A, Rhoden SA, Bernardi-Wenzel J, Orlandelli RC, et al. (2012a). Antimicrobial activity of crude extracts of endophytic fungi isolated from the medicinal plant Sapindus saponaria L. J. Appl. Pharm. Sci. 2: 35-40.

Genetics and Molecular Research 15 (4): gmr15049020 
García A, Rhoden SA, Rubin Filho CJ, Nakamura CV, et al. (2012b). Diversity of foliar endophytic fungi from the medicinal plant Sapindus saponaria L. and their localization by scanning electron microscopy. Biol. Res. 45: 139148. http://dx.doi.org/10.4067/S0716-97602012000200006

García-Salamanca A, Molina-Henares MA, van Dillewijn P, Solano J, et al. (2013). Bacterial diversity in the rhizosphere of maize and the surrounding carbonate-rich bulk soil. Microb. Biotechnol. 6: 36-44. http://dx.doi.org/10.1111/ j.1751-7915.2012.00358.x

Hallmann J and Berg G (2006). Spectrum and population dynamics of bacterial root endophytes. In: Microbial root endophytes (Schulz B, Boyle C and Sieber TN, eds.). Springer-Verlag, Berlin, Heidelberg, 15-31.

Johnston-Monje D, Lundberg DS, Lazarovits G, Reis VM, et al. (2016). Bacterial populations in juvenile maize rhizospheres originate from both seed and soil. Plant Soil 405: 337-355. http://dx.doi.org/10.1007/s11104-016-2826-0

Kemmitt SJ, Wright D, Goulding KWT and Jones DL (2006). pH regulation of carbon and nitrogen dynamics in two agricultural soils. Soil Biol. Biochem. 38: 898-911. http://dx.doi.org/10.1016/j.soilbio.2005.08.006

Keswani J and Whitman WB (2001). Relationship of 16S rRNA sequence similarity to DNA hybridization in prokaryotes. Int. J. Syst. Evol. Microbiol. 51: 667-678. http://dx.doi.org/10.1099/00207713-51-2-667.

Mendes R, Kruijt M, de Bruijn I, Dekkers E, et al. (2011). Deciphering the rhizosphere microbiome for disease-suppressive bacteria. Science 332: 1097-1100. http://dx.doi.org/10.1126/science.1203980

Miguel PSB, Delvaux JC, de Oliveira MNV, Monteiro LCP, et al. (2013). Diversity of endophytic bacteria in the fruits of Coffea canephora. Afr. J. Microbiol. Res. 7: 586-594. http://dx.doi.org/10.5897/AJMR12.2036

Morgan JAW and Whipps JM (2001). Methodological approaches to the study of rhizosphere carbon flow and microbial population dynamics. In: The rhizosphere. Biochemistry and organic substances at the soil-plant interface. 1st edn. (Pinton R, Varanini Z and Nannipieri P, eds.). Marcel Dekker, New York, 373-409.

Nacke H, Thürmer A, Wollherr A, Will C, et al. (2011). Pyrosequencing-based assessment of bacterial community structure along different management types in German forest and grassland soils. PLoS One 6: e17000. http://dx.doi. org $/ 10.1371 /$ journal.pone. 0017000

Nielsen AT, Liu WT, Filipe C, Grady L, Jr., et al. (1999). Identification of a novel group of bacteria in sludge from a deteriorated biological phosphorus removal reactor. Appl. Environ. Microbiol. 65: 1251-1258.

Pelczar MJ, Jr., Chan ECS and Krieg NR (2011). Microbiologia: Conceitos e Aplicações. 2nd edn. Pearson Education do Brasil, São Paulo.

Pelegrini DD, Tsuzuki JK, Amado CAB, Cortez DAG, et al. (2008). Biological activity and isolated compounds in Sapindus saponaria L. and other plants of the genus Sapindus. Lat. Am. J. Pharm. 27: 922-927.

Polonio JC, Almeida TT, Garcia A, Mariucci GE, et al. (2015). Biotechnological prospecting of foliar endophytic fungi of guaco (Mikania glomerata Spreng.) with antibacterial and antagonistic activity against phytopathogens. Genet. Mol. Res. 14: 7297-7309. http://dx.doi.org/10.4238/2015.July.3.5

Qi X, Wang E, Xing M, Zhao W, et al. (2012). Rhizosphere and non-rhizosphere bacterial community composition of the wild medicinal plant Rumex patientia. World J. Microbiol. Biotechnol. 28: 2257-2265. http://dx.doi.org/10.1007/ $\underline{\text { s11274-012-1033-2 }}$

Rhoden SA, Garcia A, Bongiorno VA, Azevedo JL, et al. (2012). Antimicrobial activity of crude extracts of endophytic fungi isolated from the medicinal plant Trichilia elegans A Juss. J. Appl. Pharm. Sci. 2: 57-59.

Roesch LF, Fulthorpe RR, Riva A, Casella G, et al. (2007). Pyrosequencing enumerates and contrasts soil microbial diversity. ISME J. 1: 283-290.

Schloss PD and Handelsman J (2006). Toward a census of bacteria in soil. PLOS Comput. Biol. 2: e92. http://dx.doi. org/10.1371/journal.pcbi.0020092

Schulz B and Boyle C (2005). The endophytic continuum. Mycol. Res. 109: 661-686. http://dx.doi.org/10.1017/ $\underline{\mathrm{S} 095375620500273 \mathrm{X}}$

Silva-Lacerda GR, Santana RC, Vicalvi-Costa MC, Solidônio EG, et al. (2016). Antimicrobial potential of actinobacteria isolated from the rhizosphere of the Caatinga biome plant Caesalpinia pyramidalis Tul. Genet. Mol. Res. 15: 15017488. http://dx.doi.org/10.4238/gmr.15017488

Singh BK, Bardgett RD, Smith P and Reay DS (2010). Microorganisms and climate change: terrestrial feedbacks and mitigation options. Nat. Rev. Microbiol. 8: 779-790. http://dx.doi.org/10.1038/nrmicro2439

Winston ME, Hampton-Marcell J, Zarraonaindia I, Owens SM, et al. (2014). Understanding cultivar-specificity and soil determinants of the cannabis microbiome. PLoS One 9: e99641. http://dx.doi.org/10.1371/journal.pone.0099641

Genetics and Molecular Research 15 (4): gmr15049020 